\title{
The Impact of Technology in the Field of Accounting in Small and Medium Enterpresis
}

\author{
P. Sridhar, N. Roopalatha
}

\begin{abstract}
The impact of information technology in accounting is playing a major role in small and medium enterprises information technology has been the prevailing impact to businesses and around the world.It is now given stretching from the perspective of technology and it is benefits as to whether it can be effective, that is improving small and medium enterprises performance, where many if not most of businesses implementation include competitive advantage, reduction in human errors. Companies in telangana state have different reasons for frequent improvement of technology to existing technologies used in the companies. an system application practices company outlined that the usage of technology to maximise your industrial enterprise productiveness creates the platform to recognise authentic employer success business productivity and statistics technology guarantees businesses have the equipment to conquer the challenges of executing on technique each day and prospering in gift international scenario. Small and medium enterprises business firms implements technology because it enables the company to keep up with other small and medium enterprises business firms in throughout the world. And technology allows businesses to decorate their communique strategies. using emails and awesome web web sites can help agencies beautify communique with purchaser.. This permits in retaining competitive advantage and commercial enterprise corporation owners can use generation to reduce commercial organization costs. And it enables in automating decrease lower back workplace features, for example file of ebook retaining, accounting and payroll. generation also can be used to create secure environments for maintaining sensitive organization or consumer facts. in international situation
\end{abstract}

\section{INTRODUCTION}

$T_{\text {he increasing business competition has seen many }}$ developments in how business conducts its daily business activities and how their strategies have changed due to the introduction of technology in business activities. This has affected many businesses and has led to intense business competitions locally, internationally and globally. Such were as a result of business competitions, diversification and the change in business markets and of which have been affected or impacted by technological advancements sources.

In recent times the technology have made some business organisation to exit of company due to failure to undertake of era within the region of accounting assets. applicable adoption of such era with the useful resource of business organization has visible primary upgrades into operations. generation within the situation of accounting has imported a series of parties which includes auditors, monetary managers,

Revised Manuscript Received on December 30, 2019

* Correspondence Author

Dr P. Sridhar, Assistant Professor, Department of GHBS Gitam University Hyderabad

Dr N. Roopalatha, Assistant Professor, Department of GHBS Gitam University Hyderabad, Email: roopalathareddy.irala@gitam.edu operational body of employees, bankers, customers and masses of greater. era have converted many companies in professional services industries. era has superior in a spread of areas which which include processes, laptop hardware, software languages and records constructs sources.

laptop devices have forever transformed the way businesses conduct corporation. software program applications have additionally stepped forward conventional operations and manufacturing procedures. the biggest effect technology has made on accounting is the capability of companies to develop and use automatic structures to song and report economic transactions. Paper ledgers, guide spreadsheet and hand written economic statements have all been translated into pc structures that can brief gift character transactions into economic reports.

\section{NEED FOR THE HAVE A LOOK AT}

Accounting records era are improvements in era in the region of accounting which were designed to assist within the manipulate and control of topics associated with business enterprise's financial- financial location. era have spread out the opportunity of producing and using accounting statistics from a strategic view point. The era inside the field of accounting have allowed immediately get proper of access to to services, data and statistics in addition to monetary and non-financial statistics to aid company operations. facts toll road which has been created by using new types of verbal exchange and get admission to to facts has redefined the economic organization communication. Global computer networks and telecommunications equipment allow access to all type of business information at a press of a button.

There are opportunity advantages created by the knowledge of the system and there are some types of advancements such as spread-sheets and accounting software applications skills are now essential. New developments such as e-commerce have enhanced the level of decision makers of the information technology knowledge and experience. Such developments and good utilization have increased job opportunities sources.

There is an association between accounting information structures and execution measures and premiums in such development winds up being proficient in trips to and overseeing banks, association and diverse business works out. Affiliation's costs are diminished; benefit is extended when such advancements are properly used. An affiliation's open culture to introduction to new AIS prompts an inexorably comprehensive point of view on it and a progressively essential versatility and dynamism in various leveled mission for improved results.

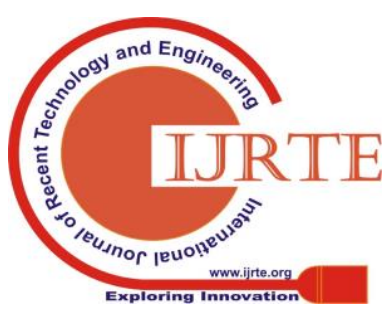


Studies have been finished about the impact of information development on an association's proficiency and gained results that have incited the indicated gainfulness peculiarity. This communicates firms grasping information advancement improvements don't seem to test enormous augmentation in their budgetary introduction as effectiveness gains are made an understanding of into preferences to customers. At any rate firms may encounter the evil impacts of productivity decay on account of the test from their it grasping accomplices.

\section{CRITICALNESS OF THE STUDY}

The assessment was depended upon to benefit individual and corporate staff who might be careless than others might be. As PCs have become standard office equipment, the staff can utilize accounting programming as exchange for standard paper records and free leaf covers.

Clerks respect the item even more habitually for example; spreadsheet programs are incredibly capable at redesigning accountant's figurings and declaring. There are accounting programs in the market in costs; this makes them to be incredibly outstanding with autonomous organizations. Dealing with tabs, recording trades and declaring are step by step tasks which should be conceivable using the item. This helps the program by keeping all data sifted through and in a united zone.Thus the research enhances the understanding of the relationship between market factors, accounting software's and programs and increased output or production levels.

\section{OBJECTIVES OF THE STUDY}

1) To choose out and check out the software program's that may be utilized by team of workers due to generation

2) to investigate the significance of technology at the same time as making alternatives

three) to provide an explanation for the impact of era to personnel for improvement.

four)to highlight how the dynamics in the present day financial surroundings have contributed to technological modifications

five) to analyze sports that manage of a technologically distressed business enterprise might also undertake to cover technical problems within the business organization.

\section{RESEARCH METHODOLOGY}

A.Collection of the data : Primary data- Primary data is data observed or collected directly through physical distribution of questionnaires and the questionnaires will be dropped at respondents, work places. Secondary data-Secondary data is collected from the different companies of various places.

B.Presentation of the data : Data will be presented using pie charts, bar graphs and tables generated by Microsoft Excel.

C.Analysis of the data : This encompasses various ways in which both primary data from the questionnaires and secondary data for case studies was analyzed.

\section{LIMITATIONS OF THE STUDY}

The study will be conducted on telagana state companies which are considered to be using high technology. These companies which will be around telagana state.

\section{ANALYSIS OF THE DATA}

Response Rate In this research, the sample consisted of accounting departments of firms from different industries such as Retail, Accounting, Service and Manufacturing industries. The distribution of responses was as shown below.

Table 1: Responded Rate

\begin{tabular}{|l|l|}
\hline Total questionnaires issued & 50 \\
\hline Total retumed & 45 \\
\hline Total unreturmed & 5 \\
\hline Percentage response & $90 \%$ \\
\hline
\end{tabular}

\section{Source of Data: Primary Data}

Fifty questionnaires were distributed to respondents, but out of fifty questionnaires forty five questionnaires were collected from different respondents, meaning the response rate was $90 \%$ which could have been attributed to physical distribution.

Data Presentation-Presentation of primary data from the questionnaire was analyzed as given below.

Awareness and benefit of technology in regards to awareness of technology, the research uncovered that a lot of companies are aware of technology. All these companies we researched from have implemented and are using technology. 98\% companies' implemented technology because of the benefits derived from the technology as shown in diagram.

The research also revealed that $93 \%$ of the companies constantly update their technology in order to be able to keep up in the industry. Technology is mostly updated to improve efficiency, increase productivity and to constantly increase the benefits of technology. The table shows that technology is mostly updated for competitive advantages.

\section{Figure 1:Awareness and benefits of technology}

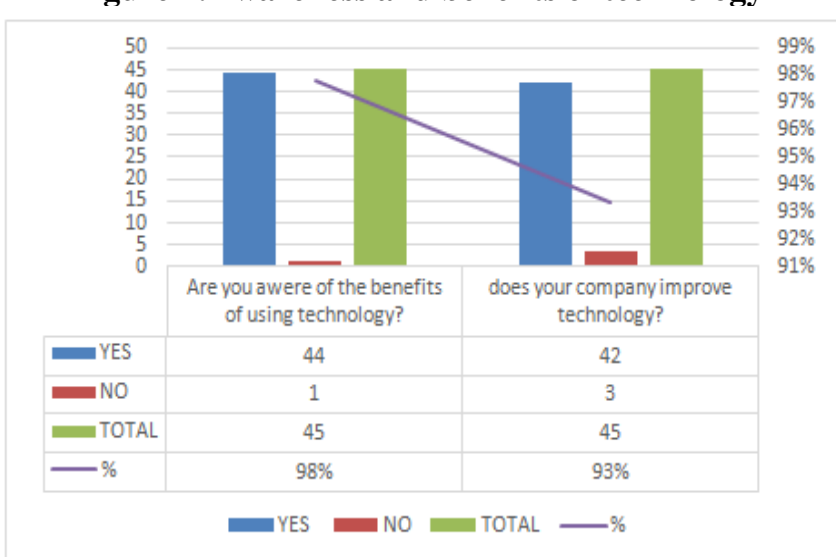

Source of Data. Primary Data.

The four following benefits shown in the table are the most common which a lot of companies implemented technology for. As seen above more companies use technology to improve speed and accuracy as compared to the other benefits of technology. 
Table 2: Awareness and benefits of technology

\begin{tabular}{|l|r|r|r|}
\hline Q1: Benefits of technology & Frequency & total & percentage \\
\hline reduce human error & 9 & 45 & $20 \%$ \\
\hline reduce crime & 9 & 45 & $20 \%$ \\
\hline improve speed & 21 & 45 & $47 \%$ \\
\hline offer new opportunities & 6 & 45 & $13 \%$ \\
\hline TOTAL & 45 & 45 & $100 \%$ \\
\hline Q2: why company improve technology & & & \\
\hline improve effeciency & 11 & 45 & $24 \%$ \\
\hline reliability & 11 & 45 & $24 \%$ \\
\hline technology benefits & 11 & 45 & $24 \%$ \\
\hline competitive advantage & 12 & 45 & $27 \%$ \\
\hline TOTAL & 45 & 45 & $100 \%$ \\
\hline
\end{tabular}

\section{Source of Data. Primary Data}

Management ensures that they implement technology based on the benefits they want to achieve. Respondents suggested that $47 \%$ companies implement technology to improve its speed for better performance and productivity. About 20\% respondents suggested that companies implement technology to reduce human error and reduce crime. Theft of information from the company can be costly to the company and so that is why companies implement to reduce crime. $13 \%$ suggested that it is implemented to offer new opportunities to the company to stay in competition with other companies.

\section{Figure2: Awareness and benefits of technology}

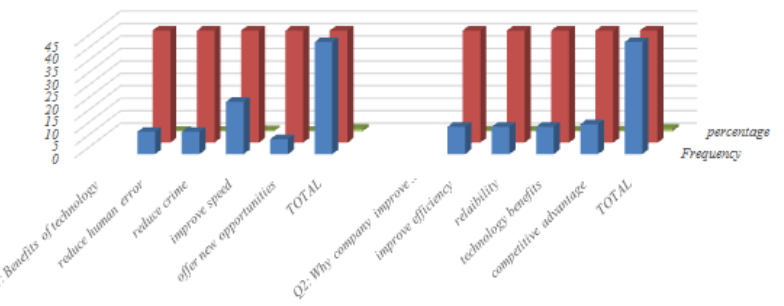

\section{Source of Data: Primary Data.}

Impact of technology on productivity and performance Technology has a lot of impact on productivity and performance of employees and of the company in the industry. Technology improves speed and accuracy of the operations such that productivity is more fast and accurate. From the data collected $46.7 \%$ of the companies stated that technology improves the speed and accuracy of their operations as compared to doing it manually. Also the data revealed that technology reduces crime in the company which improves performance of the company. Also it reduces human errors which save costs as mistakes and errors require time and funds to fix them. Technology also offers new business opportunities because of its versatility, as $20 \%$ of the companies stated that if these new business opportunities succeed this tends to increase revenue and increases the company's market share. The research also revealed that companies use technology as a competitive advantage. This means that it boosts the company's performance in the industry. $84.4 \%$ of these companies stated that technology have impacted its performance through this. With the increase in speed and accuracy companies can now produce more products and efficiently thus being able to get a larger market share. Also the more efficient the product or service is, the company is able to get a larger market share or is able to perform better than its competitors $93 \%$ companies stated that technology helps to sustain the company's position in the industry, such that if it is the leader. It can maintain that position for a long time. This is done through updating technology frequently. As technology is updated so will be the benefits obtained from it. These companies see technology as an important factor for business survival. The state that it makes communication easier which promotes growth through globalization. The research also revealed that in order for technology to be able to impact the company's performance, employees are an important factor. Without their support this objective will not be attained. Companies empower their employees through refresher courses and workshops. Also support from the IT team is important and training of employees. Empowering employees to be well equipped with technology enables the company or firm to achieve its goals faster as staff exactly what is needed of them from using technology in the company.

What the companies do to empower employees to use technology effectively:

\begin{tabular}{|c|c|c|c|c|}
\hline FACTORS & frequen & TOTAL. & \multicolumn{2}{|c|}{ Percentage } \\
\hline Training & & 32 & 45 & $71 \%$ \\
\hline wodkshops & & 5 & 45 & $11 \%$ \\
\hline supporttrom I Team & & 4 & 45 & $9 \%$ \\
\hline reffeshercourses & & 4 & 45 & $9 \%$ \\
\hline
\end{tabular}

\section{Source of Data: Primary Data}

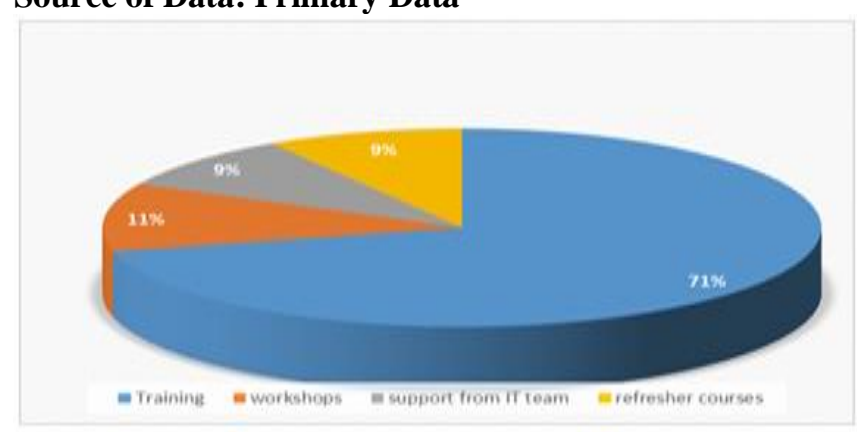

Giving relevant skills to employees ensure management and staff are in line to what is required of them by top management. As seen from the table below $71 \%$ of the companies use training to make sure employees use technology efficiently. This gives an idea of how much effort the company is doing to ensure staff members are well equipped with the advancement in technology used by the company on a daily bases. $11 \%$ use workshops to alert management and staff members on coming updates of software's and systems used in the company, $9 \%$ rely on the support from the IT team to give light on the use of software's and systems implemented in the company and $9 \%$ companies uses refresher courses which are short training programs on technology that has been updated. This type of employee empowerment keeps member staff updated on the skills they need to operate the updated system or technology

From the research it was found that there are factors that are considered to be reasons why employees find it difficult to back up the implementation of technology in the company.

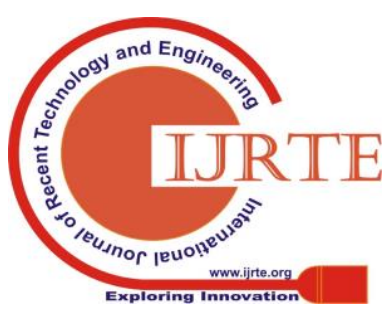


In analyzing different industries like service, manufacturing, a number of factors were used to examine the different industries. The factors below were used. 35 of $45(78 \%)$ respondents suggested that lack of skills is the leading fact why employees find it hard to back up the implementation of technology. Respondents also highlighted fear of technology as the next factor that affects employee willingness to back up technology. About $62 \%$ of the respondents pointed out this factor.

Factors affecting staff's willingness to support technology implementation

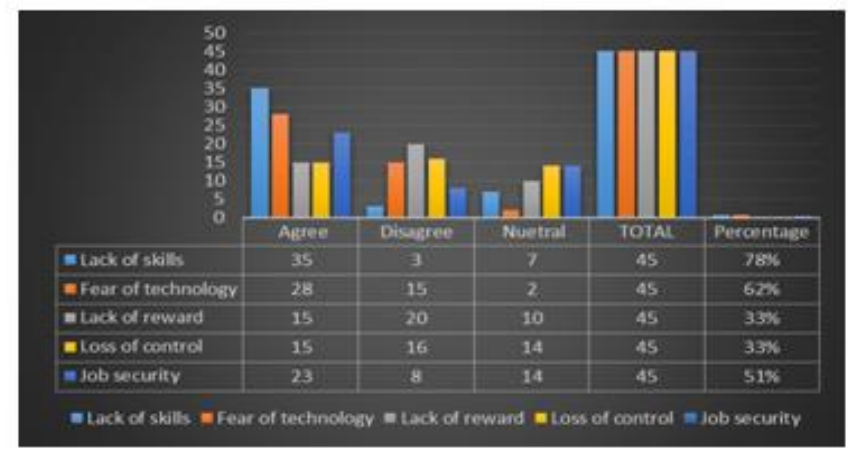

Source Data: Primary Data

The data points out that most of the respondents believe that lack of reward and loss of control are not the strong factors that makes employees find it hard to back up technology implementation. About $33 \%$ of the respondents agree with the lack of reward and loss of control which is less than those that disagree. In short most of the respondents do not believe that lack of reward and loss of control is factors that add up to the unwillingness of staff to back up IT implementation. The third factor respondents believe influence the unwillingness of staff is the worry of job security, about $51 \%$ responded to this factor.

From our primary data we examined management's reasons for implementing technology on five factors in the different industries in Telangana state. The factors are listed below in the graph chart. Management implement technology when there will be so benefit attached to it so that they do not find themselves implementing a system that will prove costly for the company. So management becomes so focused on the reasons why technology is implemented.

Factors that determine management's implementation of technology.

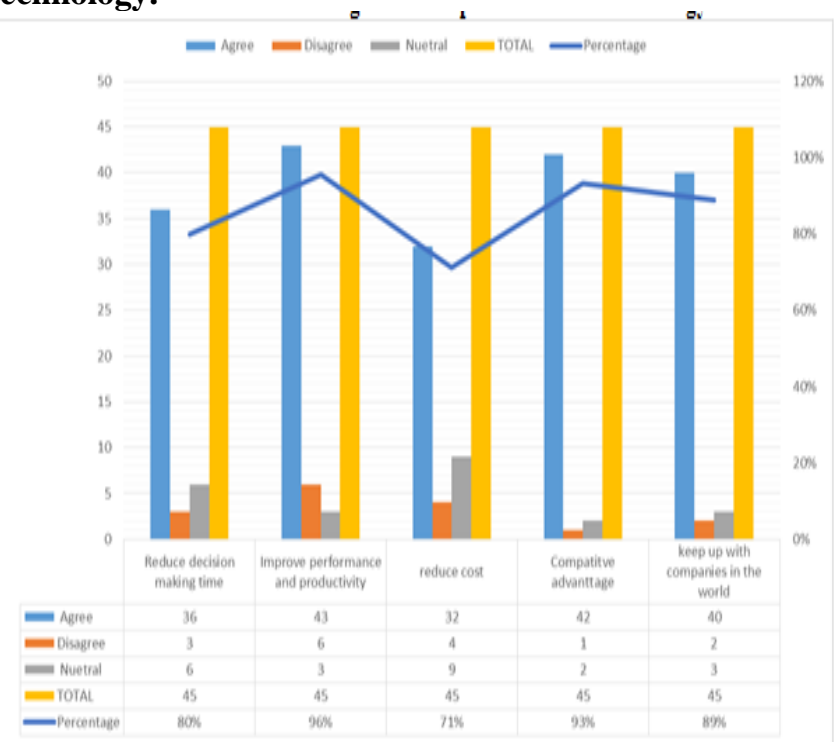

Source of Data: Primary Data
Respondents pointed out that management implement technology due to all of these factors and they are factors that management put thorough consideration on. 43 of $45(96 \%)$ respondents suggested that management implement IT to improve performance and productivity to its business and daily operations. The second most important factor was competitive advantage of the firm or business to compete with other companies in the industry, about $93 \%$ suggested this factor. $89 \%$ pointed out that management implement IT so that it enable them to keep up with other companies in the world, $80 \%$ suggested that it's because of the ability of IT to reduce decision making time and lastly about $71 \%$ pointed out reductions in costs as part of the reasons why management implement technology.

\section{CONCLUSION OF THE STUDY}

Conclusion is now given stretching from the perspective of technology and its benefits as to whether it can be effective, that is improving company performance. This was comprised of what the respondents said and what the researcher had come up with as follows;

As we gathered in our research that control put into effect generation to decorate enterprise performance, requirements and productivity. Osmond Vitez additionally confirms this as follows; He said that groups can increase their personnel' overall performance through using era. He said that pc applications and commercial enterprise software program typically allow personnel to process greater statistics than manual strategies, because of this, developing the speed and accuracy in overall performance.

This paper on fulfillment elements, an SAP company mentioned that the use of technology to maximise your business enterprise productivity creates the platform to realize real enterprise fulfillment industrial agency productiveness software software ensures agencies have the gadget to conquer the demanding situations of executing on strategy every day and prospering in nowadays's monetary instances. improved business productivity may be traced to the automation of techniques taking into account quicker communication of method, expanded time spent on sttremendousgic priorities and more task final touch fees. in step with Osmond Vitez, call for Media, he said that organization can positioned into impact business generation to expand competitive advantages in the economic market location. He cited that management must do not forget implementing era of their making plans technique with the intention to be capable of create operations the usage of the technology available.

As a richer found that control put in force technology because it permits the organization to preserve up with other companies inside the international. Osmond Vitez emphasizes this with the resource of saying that era allows organizations to improve their verbal exchange strategies. the usage of emails and different web sites can help groups beautify communique with customers. This moreover lets in organizations to reach new economic markets with the use of net advertising thru cautiously located internet banners or classified ads.

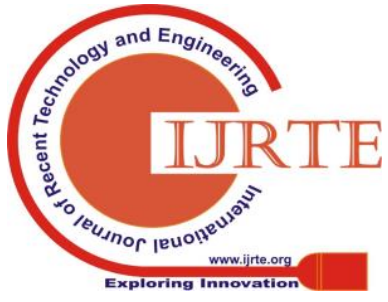


This allows in retaining aggressive gain. He additionally stated that organisation proprietors can use generation to lessen organization expenses. era enables in automating back office abilties, for instance record keeping, accounting and payroll. technology also can be used to create cozy environments for preserving sensitive enterprise or customer records.

\section{REFERENCES}

1. Boss, S.R., Kirsch, L.J., Angermeier, I., Shingle, R.A. and Boss, R.W. (2009), 'If someone is watching, I'll do what I'm asked: Mandatoriness, control, and information security', European Journal of Information Systems, Vol. 18 No. 2, pp. $151-164$

2. Brynjolfsson, E. "The Productivity Paradox of Information Technology," Communications of the ACM (36:12) 1993, pp. 66-77. Brynjolfsson, E. "The Contribution of Information Technology to Consumer Welfare," Information Systems Research (7:3) 1996, pp. 281-300

3. Brown, R.M., Gatian, A.W., and Hicks, J.O. "Strategic Information Systems and Financial Performance," Journal of Management Information Systems (11:4) 1995, pp. 215-248

4. Barua, A., Kriebel, C., and Mukhopadhyay, T. "Information Technologies and Business Value: An Analytic and Empirical Investigation," Information Systems Research (6:1) 1995, pp. 3-23.

5. Brynjolfsson, E., and Hitt, L. "IT as a Factor of Production: The Role of Differences among Firms," Economics of Innovation and New Technology (3) 1995, pp. 183- 199.

6. Baltzan, Paige, (2012). Business Driven Information System. 3 rd. Edition NY: McGraw-Hill, P. 14)

7. Coursaris, C. K., \& Kim, D. J. (2006). A qualitative review of empirical mobile usability studies. Paper presented at the 2006 Americas Conference on Information Systems (AMCIS), Acapulco, Mexico 